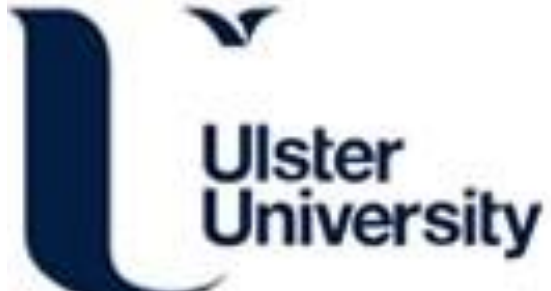

\section{Composite Microneedle Arrays Modified With Palladium Nanoclusters forElectrocatalytic Detection of Peroxide}

Davis, J., Hegarty, C., Dixon, D., Dooher, T., \& McKillop, S. (2019). Composite Microneedle Arrays Modified With Palladium Nanoclusters forElectrocatalytic Detection of Peroxide. IEEE Sensors Letters, [ 4500904]. https://doi.org/10.1109/LSENS.2019.2935831

Link to publication record in Ulster University Research Portal

Published in:

IEEE Sensors Letters

Publication Status:

Published (in print/issue): 24/09/2019

DOI:

10.1109/LSENS.2019.2935831

\section{Document Version}

Author Accepted version

\section{General rights}

Copyright for the publications made accessible via Ulster University's Research Portal is retained by the author(s) and / or other copyright owners and it is a condition of accessing these publications that users recognise and abide by the legal requirements associated with these rights.

\section{Take down policy}

The Research Portal is Ulster University's institutional repository that provides access to Ulster's research outputs. Every effort has been made to ensure that content in the Research Portal does not infringe any person's rights, or applicable UK laws. If you discover content in the Research Portal that you believe breaches copyright or violates any law, please contact pure-support@ulster.ac.uk. 


\title{
Composite microneedle arrays modified with palladium nanoclusters for electrocatalytic detection of peroxide
}

\author{
Catherine Hegarty ${ }^{1}$, Stephen McKillop ${ }^{1}$, Thomas Dooher ${ }^{1}$, Dorian Dixon ${ }^{1}$ and James Davis ${ }^{1}$ \\ ${ }^{1}$ School of Engineering, Ulster University, Jordanstown, Northern Ireland, BT37 OQB, UK
}

\begin{abstract}
Received 1 Nov 2016, revised 25 Nov 2016, accepted 30 Nov 2016, published 5 Dec 2016, current version 15 Dec 2016. (Dates will be inserted by IEEE "published" is the date the accepted preprint is posted on IEEE Xplore ${ }^{\circledR}$; "current version" is the date the typeset version is posted on Xplore $\left.{ }^{\circledR}\right)$.
\end{abstract}

\begin{abstract}
The fabrication of conductive composite microneedle (MN) patches modified with palladium clusters for the electrocatalytic detection of peroxide is described. Micro molding techniques are utilized in which carbon nanoparticles are bound within a polystyrene matrix resulting in the production of a 10x10 array of needles of length 700 micron. Electrochemical anodization of the carbon particles increases the interfacial carboxyl group population which facilitates the capture of $\mathrm{Pd} 2+$ ions. Their subsequent electroreduction yields a catalytic interface with a high sensitivity towards the electroreduction of peroxide (-0.3 V: $\left.49.7+/-2.8 \mu \mathrm{A} \mathrm{mM} \mathrm{mm}^{-1} \mathrm{~cm}^{-2} ;-0.5 \mathrm{~V}: 102.1+/-2.32 \mu \mathrm{AmM}^{-1} \mathrm{~cm}^{-2}\right)$. The microneedle sensing system and the various modification stages has been characterized using mechanical testing (fracture testing), cyclic voltammetry and high resolution $\mathrm{x}$-ray photoelectron spectroscopy.
\end{abstract}

Index Terms- Microneedle Sensors, Carbon Composites, Palladium Nanoclusters, Peroxide Detection.

\section{INTRODUCTION}

The development of microneedle (MN) arrays as a minimally invasive method of drug delivery [1-3] is well established but it is only in recent years however, that the underpinning technologies used to produce such arrays have been adapted for the development of transdermal sensors. The metalization of silicon or polymeric needles with gold or platinum has already been investigated for use in a variety of biosensing applications [4-7] but micro-molding techniques have been shown to offer a more rapid prototyping option within conventional laboratory settings [8-10]. The incorporation of nanomaterials into a suitable polymer composite matrix (typically polystyrene) can allow tailored applications and, in the case of carbon nanoparticles, conductive sensors with a rich surface chemistry ripe for further modification. The aim of the present communication has been to investigate the development of conductive carbon microneedles and their modification with palladium clusters to facilitate the highly sensitive detection of peroxide.

This approach relies on nano-structuring the carbon surface through the electrochemical exfoliation of the interfacial carbon nanoparticles that comprise the conductive elements within the array $[8,9]$. This should have the effect of increasing both the proportion of edge plane sites and the population of oxygen functionalities principally carboxylate groups. The latter can then be used to passively chelate palladium (II) ions from solution which, when placed in fresh buffer, can be electrochemically reduced to yield discrete nano clusters of palladium. It was anticipated that this templating methodology would minimize aggregation associated with dispersal of preformed nanoparticles on to electrode surfaces. The strategy adopted in this work is highlighted in Fig 1.

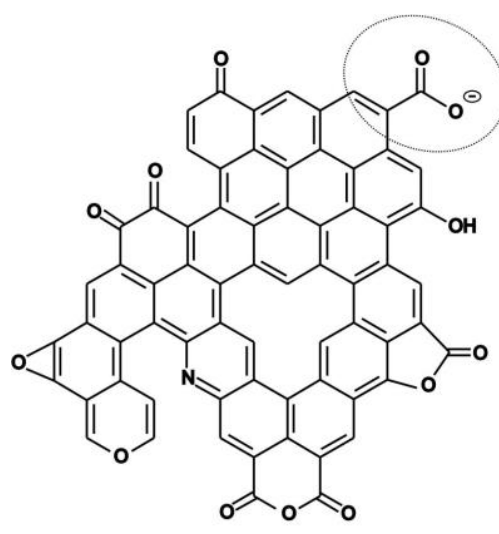

Anodised Carbon Particle

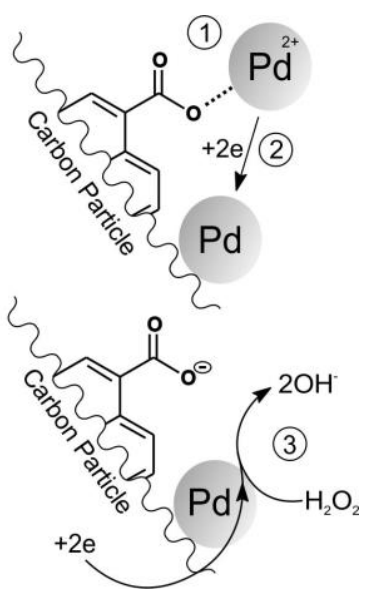

Fig. 1. Mechanism of Palladium catalyzed peroxide reduction at the anodized carbon microneedle interface. Capture of $\mathrm{Pd}^{2+}$ through coordination with carboxyl moieties (1). Electroreduction of $\mathrm{Pd}^{2+}$ to $\mathrm{Pd}$ metal (2). Electroreduction of peroxide at the Pd clusters immobilized on the microneedle surface(3).

Previously, silver, gold and platinum have been validated as favorable metals in the detection of $\mathrm{H}_{2} \mathrm{O}_{2}$ [4-7]. However, palladium is emerging as a superior choice of metal due to the comparable low cost, robustness and superior electron transfer characteristics [11-19]. While the application of $\mathrm{Pd}$ to electrode designs for $\mathrm{H}_{2} \mathrm{O}_{2}$ sensing is ever growing, it has long been recognized that the size, shape and structure of metallic nanoparticles will affect electrocatalytic performance [18]. Thus, it was anticipated that the large surface area to volume ratio of metallic nanoparticles would amplify sensitivity during electrochemical analyses [19]. 


\section{MICRONEEDLE FABRICATION}

Carbon nanoparticles (cnp) (Sigma UK) were combined with polystyrene beads (192,000 average Mw Sigma) in a ratio of 50:50 by weight, dissolved in cyclohexanone and stirred until a homogenous solution was obtained (typically 2 hours). The solution was cast into Micropoint ${ }^{\circledR}$ silicone templates (200 (base) x 500 (pitch) x 700 (height) $\mu \mathrm{m}$ covering a $10 \times 10$ needle array) as indicated in Fig 2. Templates were placed in a vacuum at $30^{\circ} \mathrm{C}$ and once the pressure had increased to 1000 mbar, air was released to draw the homogenous solution to the tips of the silicone cast ensuring sharp microneedle production. The solvent was left to evaporate at room temperature (over $48 \mathrm{~h}$ ) whereupon the needles could be removed from the template. The baseplate and non-needle surfaces were coated with enamel ( $6 \mathrm{~h}$ drying period) to serve as a dielectric and define the geometric electrode area $\left(0.49 \mathrm{~cm}^{2}\right)$.

\section{MICRONEEDLE CHARACTERISATION}

Scanning electron micrographs detailing the morphological features of the composite microneedle systems after casting carbonpolystyrene microneedles (50:50 wt/wt) are highlighted in Fig. 2A. The needles have a high aspect ratio and an average tip width of 2.5 micron $(\mathrm{N}=10)$. The polystyrene binder provides a smooth surface structure and stands in contrast to previous reports of composite needles consisting of metallic Pd particles enmeshed within a polycarbonate/polystyrene matrix where a granular morphology was evident [8].

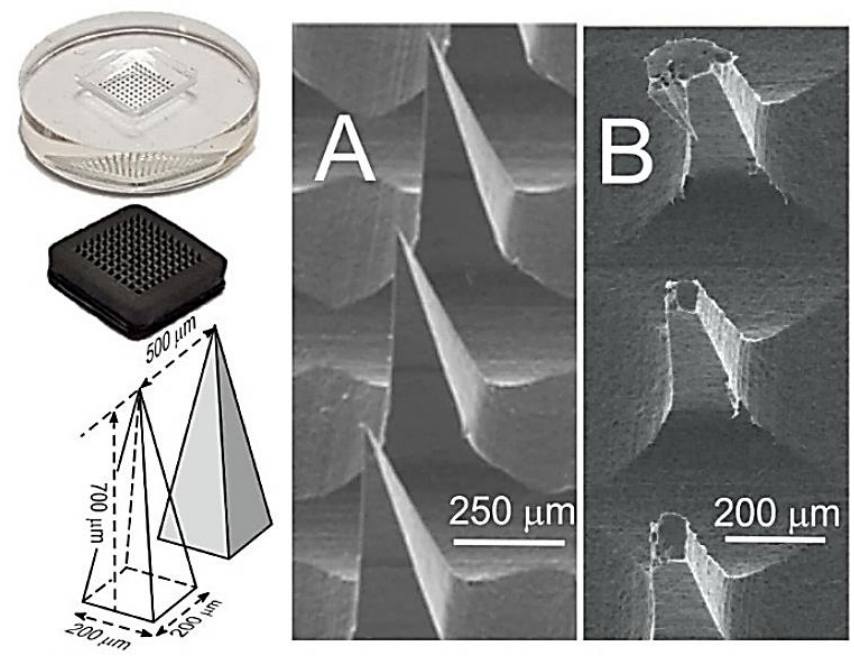

Fig 2. Micropoint ${ }^{\circledR}$ silicone micro molding template and resulting carbonpolystyrene microneedle array. Scanning electron micrographs of the MN array before (A) and after fracture testing (B).

It could be assumed that a high concentration of carbon to polymer ratio would improve the conductivity of the MN array, however, a balance is required between the conductive functionality and maintaining the mechanical structure of the array. The 50:50 carbonpolystyrene microneedle patches were found to be optimal and the conductivity measured using 2461 series SourceMeter ${ }^{\circledR}$ (Keithley) 4 point probe and found to be $1575.2 \mathrm{~S} / \mathrm{m} \pm 96 \mathrm{~S} / \mathrm{m}(\mathrm{N}=5)$.

\section{FRACTURE TESTING}

The force required to mechanically fracture the microneedle was measured using an axial load test station (Instron ${ }^{\circledR}$ 3344, Buckinghamshire, UK) with a $50 \mathrm{~N}$ load cell. A round metal rod with a diameter of $10 \mathrm{~mm}$ was driven into the microneedle array at a rate of $0.01 \mathrm{~mm} / \mathrm{s}$ until fracture occurred. The mechanical integrity of the needles was assessed under compression and the mean axial force required to fracture the $\mathrm{MN}$ tips within the array was found to be 11.35 $\mathrm{N}+/-0.91 \mathrm{~N}$ (based on 5 discrete samples) which equates to $0.1 \mathrm{~N}$ per needle. Olatunji et al (2013) have shown that the forces required for reliable insertion through skin tend to reside within the range of 0.028 $\mathrm{N}$ and $0.03 \mathrm{~N}$ which are comfortably lower than the fracture force in the composite system investigated here [20].

\section{MICRONEEDLE MODIFICATION}

Electrochemical anodisation $(+2 \mathrm{~V}, 0.1 \mathrm{M} \mathrm{NaOH})$ was performed on the carbon based $\mathrm{MN}$ patches in order to promote the formation of interfacial carboxyl groups necessary for the capture of the palladium ions [8,9]. Oxidation of carbon fibers and the production of a large variety of chemical moieties (Fig 1) is well established and it was expected that a similar process would result with the carbon composite formulation used in the production of the needles. Modification of the interfacial carbon particles surface was assessed through X-ray photoelectron spectroscopy (XPS) using a Kratos Axis Ultra DLD spectrometer. Spectra were analyzed using monochromated $\mathrm{Al} \mathrm{K \alpha}$ X-rays $(\mathrm{hv}=1486.6$ electron volts $(\mathrm{eV})$ ) operating at $14 \mathrm{kV}$ and $10 \mathrm{~mA}(140 \mathrm{~W})$. A hybrid lens mode was used (electrostatic and magnetic) with a $300 \mu \mathrm{m} \times 700 \mu \mathrm{m}$ analysis area and a take off angle (TOA) of $90^{\circ}$ with respect to the sample surface. Wide energy survey scans (WESS) were collected across $0-1200 \mathrm{eV}$ binding energy (BE), with a pass energy of $160 \mathrm{eV}$. High resolution spectra were collected with a pass energy of $40 \mathrm{eV}$. A charge neutralizer system with a filament current of $1.95 \mathrm{~A}$ and a charge balance between $3.3 \mathrm{~V}-3.6 \mathrm{~V}$ was used for all samples. Charging effects on the BE positions were adjusted by setting the lowest BE for the $\mathrm{C} 1 \mathrm{~s}$ spectral envelope to $284.8 \mathrm{eV}$, which is commonly accepted as adventitious carbon surface contamination [21,22]. Peak fitting of high resolution spectra was carried out using Casa XPS software.

Typical high resolution $\mathrm{C} 1 \mathrm{~s}$ spectra highlighting the carbon functional groups pre and post anodization are detailed in Fig 2A respectively along with the associated peak fitting. The $\mathrm{C} 1 \mathrm{~s}$ spectra of the unmodified carbon needle surface is largely $\mathrm{sp}^{2} / \mathrm{sp}^{3}$ due to the graphitic nature of the carbon particles and the polystyrene binder. Once oxidized (Inset Fig 2A), a greater proportion of carbon-oxygen functionality emerges with the percentage of carboxyl groups increased from a negligible level to almost 3\%. The profiles are similar in nature to previous reports of electrochemical and plasma treatment of carbon substrates where the $\mathrm{sp}^{2}$ components associated with the basal structures are oxidized leading to a variety of $\mathrm{C}-\mathrm{O}$ groups [23]. In this particular case, the change in the $\mathrm{sp}^{2}$ peak is less dramatic due to the predominance of the phenyl ring in the polystyrene binder which will be unchanged upon anodisation. The increase in the carboxyl functionality is however critical to the overall electrode modification strategy. 
The presence of chelating groups at electrode interfaces has been shown to enable the passive capture of metal ions which can then be converted to nanoparticulate clusters through the addition of a appropriate reducing agent (typically $\mathrm{NaBH}_{4}$ or hydrazine) [24-27]. In this case, palladium was successfully chelated by the carboxylate groups at the MN surface through immersing the anodized MN into a solution of $1 \mathrm{mM}$ sodium tetrachloropalladate (II) for 10 minutes followed by rising with copious amounts of deionized water. The MN were then held at a reducing potential to electrochemically convert the $\mathrm{Pd}^{2+}$ to $\mathrm{Pd}$ metal. X-ray photoelectron spectra of the MN pre and post exposure to $\mathrm{Pd}^{2+}$ (and after electroreduction) are compared in Fig 3B. The typical double peak associated with the $\mathrm{Pd} 3 \mathrm{~d} 3 / 2$ and $\mathrm{Pd} 3 \mathrm{~d} 5 / 2$ components with the observed binding energies of $334.96 \mathrm{eV}$ and $340.26 \mathrm{eV}$ respectively found to be in good agreement with the expected values for $\mathrm{Pd}^{\circ}[28,29]$. The relative elemental surface composition found that the $\mathrm{Pd}$ component was 0.85 atomic\% concentration $(\mathrm{N}=3)$. This was expected, since it is not a layer of $\mathrm{Pd}$ deposited on the surface but rather a dispersion of Pd nanoclusters.

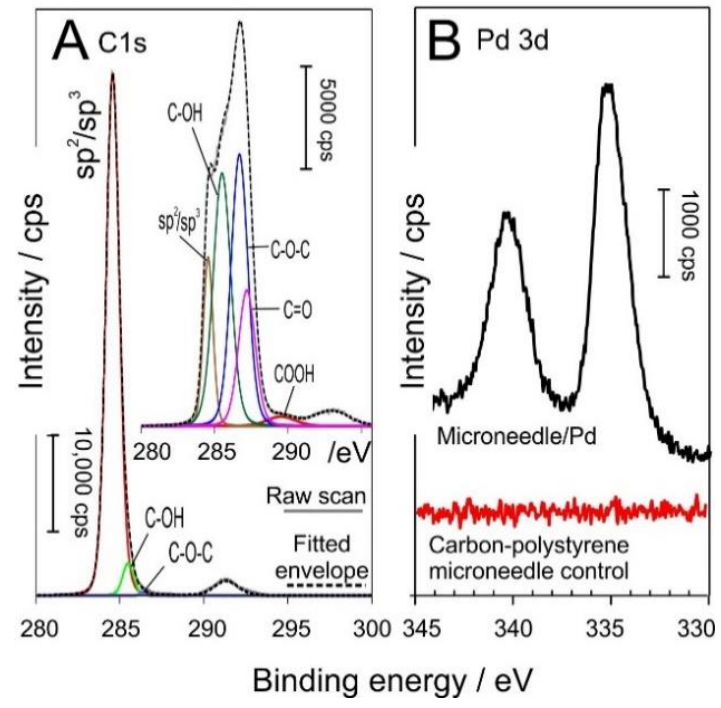

Fig 3. X-ray photoelectron spectra (A) of the carbon composite microneedle before and after (Inset) electrochemical anodization and (B) XPS confirming the capture and reduction of $\mathrm{Pd}^{2+}$ to $\mathrm{Pd}^{0}$ at the $\mathrm{MN}$ surface.

\section{RESULTS AND DISCUSSION}

The sensitivity to hydrogen peroxide was tested in increasing concentrations of $\mathrm{H}_{2} \mathrm{O}_{2}$ in $\mathrm{pH} 7$ buffer solution by cyclic voltammetry $(+0.8 \mathrm{~V}$ to $-0.8 \mathrm{~V}$ at $50 \mathrm{mV} / \mathrm{s})$. Cyclic voltammograms comparing the response of the MN array to peroxide pre and post Pd modification are shown in Fig 4. The blank response of the Pd modified MN array exhibits both reduction $(-0.034 \mathrm{~V})$ and oxidation $(-0.371 \mathrm{~V})$ peak processes in the absence of peroxide and is consistent with previous investigations examining Pd clusters at modified electrodes [24-26]. The addition of peroxide to the Pd system leads however to a marked increase in the reduction response (especially in comparison to the unmodified MN control). An oxidative process is also observed but it is clear from Fig 4 that its sensitivity is considerably less than the reduction process.

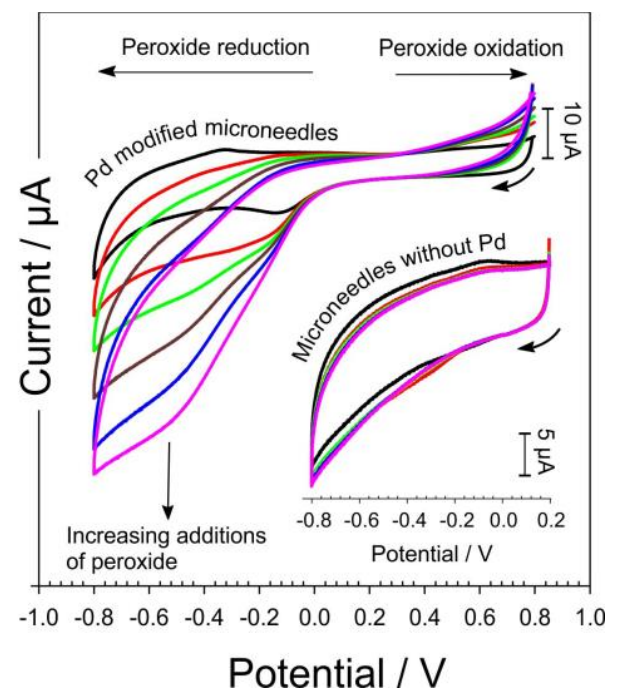

Fig 4. Cyclic voltammograms detailing the response of a Pd modified carbonpolystyrene microneedle array towards peroxide $(0$ to $500 \mu \mathrm{M})$ in $\mathrm{pH} 7$ Britton-Robinson buffer. Inset: unmodified microneedle response to peroxide under similar conditions. Scan rate: $50 \mathrm{mV} / \mathrm{s}$. Voltages recorded relative to a $3 \mathrm{M} \mathrm{Ag} \mid \mathrm{AgCl}$ half cell.

There is an extensive literature base on the use of nanoparticles to confer selective and sensitive responses to peroxide $(-0.3 \mathrm{~V}: 49.7 \pm$ $\left.2.8 \mu \mathrm{A} \mathrm{mM}{ }^{-1} \mathrm{~cm}^{-2} ;-0.5 \mathrm{~V}: 102.1 \pm 2.32 \mu \mathrm{A} \mathrm{mM}^{-1} \mathrm{~cm}^{-2} ; \mathrm{N}=3\right)$ and some of these are included in Table 1 for comparison. It is clear from Fig 4 that the Pd modified microneedle array is superior to the bare, unmodified carbon system but it is also evident that it is also competitive with many of those listed in Table 1.

Table 1. Electrode sensitivity towards Peroxide

\begin{tabular}{|c|c|c|c|}
\hline Electrode Type & $\begin{array}{c}\text { Detection } \\
\text { Potential } \\
\text { / V }\end{array}$ & $\begin{array}{r}\text { Sensitivity } \\
\mu \mathrm{A} \mathrm{mM}^{-1} \mathrm{~cm}^{-2}\end{array}$ & Ref \\
\hline Nafion Pd C-F & +0.8 & 27.71 & 8 \\
\hline PdNPs-MWCNTs/GCE & +0.35 & 0.17 & 11 \\
\hline $\mathrm{ZnO} / \mathrm{CO}_{3} \mathrm{O}_{4} / \mathrm{NiCO}_{2} \mathrm{O}_{4} / \mathrm{Ni}$ & +0.55 & 388.00 & 12 \\
\hline Co3O4 NPs & +0.2 & 72.75 & 13 \\
\hline $\mathrm{Pd} \mathrm{C-F}$ & -0.2 & 148.89 & 8 \\
\hline ER-GNO/IL-SPE & -0.2 & 78.13 & 14 \\
\hline $\mathrm{rGO} / \mathrm{ZnO} / \mathrm{GCE}$ & -0.38 & 0.01 & 15 \\
\hline Nafion/CAT/rGO/GCE & -0.45 & 7.76 & 16 \\
\hline $\mathrm{Au}-\mathrm{Pd} / \mathrm{MoS}_{2} / \mathrm{GCE}$ & -0.1 & 184.90 & 17 \\
\hline Pd/C Microneedle & $-0.3 \mathrm{~V}$ & 49.7 & TW \\
\hline Pd/C Microneedle & $-0.5 \mathrm{~V}$ & 102.1 & TW \\
\hline
\end{tabular}

Where: TW = This work; ER-GNO= electrochemically reduced graphene oxide; $\mathrm{rGO}$ = reduced graphene oxide; $\mathrm{IL}=$ ionic liquid; SPE = screen printed electrode; GCE = glassy carbon electrode; $\mathrm{MWCNT}$ = multiwall carbon nanotube; $\mathrm{C}-\mathrm{F}=$ carbon fiber; $\mathrm{CAT}=$ catalase

Given the response of the unmodified MN array to peroxide (Inset Fig 4 ), it is clear that sensitivity depends on presence of Pd. It could be anticipated that increasing the proportion of carboxyl groups beyond the 3\% found here, would increase Pd loading and thereby improve the response. In practice, increasing the anodization time (even up to 
$1 \mathrm{~h}$ ) was found to have little influence on the interfacial carboxyl group population and can be attributed to the competing processes of chemical modification and physical exfoliation of the modified (now hydrophilic) lattice components from the graphitic particle. Alternative (chemical) methods of incorporating carboxyl functionalities at the carbon interface may however offer a more effective means through which this limitation could be overcome.

\section{CONCLUSIONS}

The ability to rapidly fabricate conductive composite microneedle patches by micro-molding in silicone templates has proven to be significantly advantageous over alternative micro-machining techniques. The ability to directly chelate $\mathrm{Pd}$ to the anodized microneedle electrode surface was demonstrated as a highly effective and sensitive peroxide sensor. In turn, the facile means of depositing a metallic catalyst for peroxide detection paves the way for exploring the immobilization of $\mathrm{H}_{2} \mathrm{O}_{2}$ sensitive enzymes to the electrode interface (i.e. glucose oxidase). The ability to exploit the reduction process as the mean of monitoring peroxide avoids inducing the oxidation of other electroactive species present within biofluids (i.e. ascorbate, urate, tyrosine). Such processes would otherwise contribute to the current leading to over estimation of the peroxide concentration (and thereby the enzyme substrate).

\section{ACKNOWLEDGMENT}

The authors are pleased to acknowledge financial support from the European Union's INTERREG VA Programme, managed by the Special EU Programmes Body (SEUPB) and the Department for the Economy (DfE) Northern Ireland

\section{REFERENCES}

[1] Rzhevskiy AS, Raghu T, Singh R, et al. (2018) Microneedles as the technique of drug delivery enhancement in diverse organs and tissues. Journal of Controlled Release, 270, pp184-202. doi: 10.1016/j.jconrel.2017.11.048.

[2] Ita K (2018) Ceramic microneedles and hollow microneedles for transdermal drug delivery: Two decades of research. Journal of Drug Delivery Science and Technology, 44, pp 314-322. doi: 10.1016/j.jddst.2018.01.004.

[3] Donnelly RF and Larrañeta E (2018) Microarray patches: potentially useful delivery systems for long-acting nanosuspensions. Drug Discovery Today, 23, pp 1026-1033. doi: 10.1016/j.drudis.2017.10.013.

[4] Barrett C, Dawson K, Mahony CO, O'Riordan A (2015) Development of Low Cost Rapid Fabrication of Sharp Polymer Microneedles for In Vivo Glucose Biosensing Applications. ECS J. Solid State Sci. Technol., 4, pp 3053-3058. DOI: $10.1149 / 2.0141510$ jss.

[5] Bok K, Lee W, Cho C, Park DS, Cho SJ, Shim YB (2019) Continuous glucose monitoring using a microneedle array sensor coupled with a wireless signal transmitter. Sensors \& Actuators: B. Chemical, 281, pp 14-21. DOI: 10.1016/j.snb.2018.10.081.

[6] Chinnadayyala SR, Park I and Cho S (2018) Nonenzymatic determination of glucose at near neutral $\mathrm{pH}$ values based on the use of nafion and platinum black coated microneedle electrode array. Microchim Acta, 185: 250. https://doi.org/10.1007/s00604-018-2770-1

[7] Sharma S, Huang Z, Rogers M, Boutelle M, Cass AEG. (2016) Evaluation of a minimally invasive glucose biosensor for continuous tissue monitoring. Analytical and Bioanalytical Chemistry. 408, pp 8427-8435. DOI: 10.1007/s00216-0169961-6.

[8] McConville A, Davis J (2016) Transdermal microneedle sensor arrays based on palladium: Polymer composites. Electrochemistry Communications, 72, pp 162-
165. DOI: 10.1016/j.elecom.2016.09.024.

[9] Hegarty C, McConville A, McGlynn RJ, Mariotti D, Davis J, (2019) Design of composite microneedle sensor systems for the measurement of transdermal $\mathrm{pH}$, Materials Chemistry and Physics, 227, pp 340-346

[10] Hegarty C, McKillop S, McGlynn RJ, Smith RB, Mathur A, Davis J, (2019) Microneedle array sensors based on carbon nanoparticle composites: interfacial chemistry and electroanalytical properties, J Mater Sci, 54, pp 10705-10714

[11] H. Hamidi, B. Haghighi, (2016) Fabrication of a sensitive amperometric sensor for NADH and $\mathrm{H}_{2} \mathrm{O}_{2}$ using palladium nanoparticles-multiwalled carbon nanotube nanohybrid, Materials Science and Engineering C, 62, pp 423-428.

[12] Xue B, Li K, Gu S, Zhang L, Lu J, (2018) Ni foam-supported ZnO nanowires and $\mathrm{Co}_{3} \mathrm{O}_{4} / \mathrm{NiCo}_{2} \mathrm{O}_{4}$ double-shelled nanocages for efficient hydrogen peroxide detection, Sensors and Actuators B, 262, pp 828-836.

[13] Ni Y, Liao Y, Zheng M, Shao S, (2017) In-situ growth of $\mathrm{Co}_{3} \mathrm{O}_{4}$, nanoparticles on mesoporous carbon nanofibers: a new nanocomposite for non-enzymatic amperometric sensing of $\mathrm{H}_{2} \mathrm{O}_{2}$, Microchim. Acta, 50, pp 1-7.

[14] Ping J, Wang Y, Fan K, Wu J, Ying Y, (2011) Direct electrochemical reduction of graphene oxide on ionic liquid doped screen-printed electrode and its electrochemical biosensing application, Biosens. Bioelectron. 28, pp 204-209.

[15] Palanisamy S, Chen SM, Sarawathi R, (2012) A novel non-enzymatic hydrogen peroxide sensor based on reduced graphene oxide / $\mathrm{ZnO}$ composite modified electrode, Sensors Actuators B Chem. 166, pp 372-377.

[16] Ting SW, Periasamy AP, Chen SM, Saraswathi R, (2011) Direct electrochemistry of catalase immobilized at electrochemically reduced graphene oxide modified electrode for amperometric $\mathrm{H}_{2} \mathrm{O}_{2}$ biosensor, Int. J. Electrochem. Sci. 6, pp 44384453

[17] Li X, Du X, (2017) Molybdenum disulfide nanosheets supported Au-Pd bimetallic nanoparticles for non-enzymatic electrochemical sensing of hydrogen peroxide and glucose, Sensors and Actuators B, 239, pp 536-543

[18] Tang Y, Cheng W.(2013) Nanoparticle-modified electrode with size- and shapedependent electrocatalytic activities. Langmuir, 29, pp 3125-32.

[19] Baccar H, Adams CP, Abdelghani A, Obare SO (2013) Chronoamperometric-based detection of hydrogen peroxide using palladium nanoparticles, International Journal of Nanotechnology, 10, DOI: 10.1504/IJNT.2013.053525

[20] Olatunji O, Das DB, Garland MJ, Belaid L, Donnelly RF (2013) Influence of array interspacing on the force required for successful microneedle skin penetration: theoretical and practical approaches., J Pharm Sci., 102, pp 1209-21. doi: $10.1002 /$ jps. 23439 .

[21] ASTM. Standard Guide to Charge Control and Charge Referencing Techniques in X-Ray Photoelectron Spectroscopy. Astm. 2003;i:1-7.

[22] National Institute of Standards and Technology (NIST). NIST X-ray Photoelectron Spectroscopy (XPS) Database, Version 3.5 [Internet]. NIST Standard Reference Database 20, Version 4.1. 2012 [cited 2018 Oct 15]. Available from: https://srdata.nist.gov/xps/

[23] Anderson A, Phair J, Benson J, Meenan B, Davis J. (2014) Investigating the use of endogenous quinoid moieties on carbon fibre as means of developing micro $\mathrm{pH}$ sensors. Materials Science Engineering $C$ 43, pp 533-7. Doi: 10.1016/j.msec.2014.07.038

[24] Chen X, Chen XM, Cai ZX, Huang ZY, Oyama M, Jiang YQ. (2013) Ultrafine palladium nanoparticles grown on graphene nanosheets for enhanced electrochemical sensing of hydrogen peroxide. Electrochim Acta, 97, pp 398-403. doi:10.1016/j.electacta.2013.02.04

[25] Gupta R, Singh P, Ganesan V, Koch B, Rastogi PK, Yadava, Sonkar PK, (2018) Palladium nanoparticles supported on mesoporous silica microspheres for enzymefree amperometric detection of $\mathrm{H} 2 \mathrm{O} 2$ released from living cells, Sensors \& Actuators: B. Chemical, 276, pp 517-525

[26] Bozkurt S, Tosun B, Sen B, Akocak S, Savk A, Ebeoglugil MF, Sen F (2017) A hydrogen peroxide sensor based on TNM functionalized reduced graphene oxide grafted with highly monodisperse Pd nanoparticles, Analytica Chimica Acta, 989 , pp 88-94

[27] Baghayeri M, Amiri A, Razghandi H, (2019) Employment of Pd nanoparticles at the structure of poly aminohippuric acid as a nanocomposite for hydrogen peroxide detection, Journal of Electroanalytical Chemistry 832, pp 142-151

[28] Rastogi PK, Ganesan V, Krishnamoorthi S, (2014) Palladium nanoparticles incorporated polymer-silica nanocomposite based electrochemical sensing platform for nitrobenzene detection, Electrochim. Acta, 147,pp 442-450.

[29] Rastogi PK, Ganesan V, Krishnamoorthi,S, (2014) Palladium nanoparticles decorated gaur gum based hybrid material for electrocatalytic hydrazine determination, Electrochim. Acta, 125, pp 593-600. 